\title{
Iranian Women's Identity and Cyberspace: Case study of Stealthy Freedom
}

\author{
Sedigheh Karimi \\ University of Melbourne, Australia \\ E-mail: sedighehk@student.unimelb.edu.au
}

Received: September 8, $2014 \quad$ Accepted: October 6, $2014 \quad$ Published: November 7, 2014
doi:10.5296/jsss.v2i1.6284

\begin{abstract}
Gender related identity formation of women has been influenced by numerous parameters in recent years. The status of women in Iran today is not comparable to that in the past. Significant changes have occurred as communities and households respond to social and economic shifts associated with globalization, new technologies and environmental pressures. What is obvious is that, along with the globalization and current social and intellectual upheavals, society and women both have adopted a more transitory and unbalanced attitude towards women's gender identity. Of the most remarkable factors impacting on this shift in attitude has been the role of mass media, modern media such as the internet in particular.

Meanwhile among the different views of identity, there is often a shared assumption that the ways in which identity is defined and hence what counts as identity are undergoing far-reaching changes in the contemporary world. This is certainly debatable, but it does imply that one place to look for evidence of change would be women, and perhaps specifically their relation with new technologies. Therefore, I intend to raise some broad points about how we understand digital technology, women and their relationship.

This paper first explores theoretical perspectives on cyberfeminism within the definition of identity and its relation with gender. Then the formation of female identity and its elements in regard with media will be contemplated. The most essential aim is investigating women's gender identity and its relevance to media, modern media such as the internet in particular. For this study I examine women's representation in media particularly the internet with a focus on stealthy freedom campaign which allow me to show how Iranian women are shaping their identity quit apart from the pressure of a male dominated society that will provide further insight into this unresolved question.
\end{abstract}

The study of the impact of media on women's identity and an analysis of the due changes 
together with suggesting strategies to navigate towards this impact will be other serious concerns.

Keywords: Identity, Iranian women, Cyberfeminism, Media

\section{Introduction}

There have been observable changes in recent years regarding investigating women's issues in Iran. Iranian woman's identity is an amalgamation of tradition and modernity. In such an atmosphere, Iranian women are attempting to redefine their identity through a traditional or modern attitude or combination of both. In Iran's society today, identities have transformed as traditional ones have been challenged whereas new identities have been formed which enjoy neither the solidity nor the stability of that of the past. Cyberspace is one of the major elements responsible for identity change today as in women's lives in Iran. Through introducing cultural underpinnings these media form the common sense of the society in accordance with their own patterns bringing about major upheavals in their attitudes.

By connecting local conditions of Iran to global forces by means of new media, young Iranians are challenging the authoritarian measures that limit individual rights and civil liberties (Nouraie-Simone, 2005). Virtually connected made it possible for them to write about their ideas and demands without the fear of censorship or chastisement. The astonishing trend shows that Iran is the world's fourth largest country of bloggers with approximately 60,000 Persian blogs (Asemi, 2006). Moreover they are able to create a virtual identity for themselves without the fear of being recognized and consequently being punished. They could now freely reveal their "hidden" self. In this regards the self becomes a kind of project that women are working on through the internet. To Anthony Giddens (1991) this is a positive development and also a mostly comprehensive process of democratization; modern consumerism culture has offered individuals multiple potentials to construct and shape their own identities, which they are now able to do this in increasingly creative and diverse ways.

The effective role of the internet in social life and its influential impact on forming identity has caused the pre-existing differences concerning identity, perspectives and behavioural patterns be examined via a new look. New directions in social theory are more complex, decentralized and fluid due to the fact that technological, social and cultural developments in public and private life are now rapidly changing the nature of human studies. While using communication media, people use certain types of interaction which differs from face to face interaction in specific ways (Thompson, 2001). Online environments can even contribute to furthering the fragmentation of identity (Kolko, Nakamura, \& Rodman, 2000). These media have transformed the social life fundamentally. How do people reveal their identity in these new channels of interaction? (How) do cyberspaces which shape a new mode of mutual interaction, modify the meaning of gender identity and gender?

Social communication sciences are concern about areas such as women's studies and media which can be studied through various angels such as:

1. Women's status in media organisations and their roles in producing media content

2. Women as the interlocutors or targets of media

3. The representation of women in media

Each of these areas is undoubtedly interacting with the others and is thus indispensible. Here 
it seems the concept of reflection as a more crucial one has more to do with aspects 1 and 2 in women's studies, provided that both media production and consumption are related to identity reflection (Pilcher \& Whelehan, 2005). Thus, regarding the significance of medium in women's attitude towards gender identity, the following question is raised:

What relation exists among consumption pattern, motivation to use and amount of consumption of media on the one hand, and women's attitude to their gender identity on the other?

In order to examine the main question of this paper, internet is one of the major sources of identity change in women's life in today's world. As a result it seems necessary to define the current academic interpretations of identity and media. So, the pertinent definition in this chapter is presented. Each of these interpretations uses certain introductory elements in their definitions which will be analysed in the rest of the paper, and then in the next stage women's status in media will be reflected. Keeping this in mind, this paper employs a feminist perspective throughout analysing these issues using a gendered lens.

\subsection{Identity}

The word identity originated from Latin has two major meanings. The first represents the concept of absolute sign and the second signifies an absolute difference. Hence the concept of identity establishes two distinct relations between people or objects simultaneously during which similarity and difference of personal identity in relation between self-conceptions and public images are created (Jenkins, 2003). Stuart hall (1996) has presented three definitions of identity which retells the chronological evolution of that from enlightenment to post-modernity.

- Human being is a wholly integrated entity full of intellectual potentials (public sense).

- During the enlightenment era, an extremely individualistic identity is presented. In addition the subject is deemed male in defining (Hall \& Geben, 1992). This type of identity is shaped in relation to the others. In this perspective, the subject's identity is manipulated by the social life of people and that identity is always being formed (does not pre-exist).

- The subject has no stable intrinsic identity and is constantly formed and reshaped by reflecting methods as well as media-cultural institutions around us.

It needs to be emphasised that identity is different from personality or persona. We might share our personality traits with others. However, commonality in identity refers to some of our deeds. We are specified through our personal characteristics, but known via our identity (Woodward, 2000). Therefore identity could be defined via answering the two questions; how I define myself and how others define me. These two questions reveal that identity is partly made by self and partly by others. In fact, identity is a notion which is in relation with the internal and external world. While in postmodern paradigm, identity is an amalgamation of cultural assumptions, values and models which brings about solidity and continuity of numerous selves in us all our lives (Freud, 2001). Consequently identity can have the following characteristics:

1. It relates to how I see myself and how others see me

2. It relates to individual and society

3. It is identified through similarity and difference 
4. It can be unit or multi-faceted

5. It can be static, fluid or changing (Woodward, 2000)

Thus according to the above elements and parameters, a framework is introduced for defining identity. We could also make use of Jenkins's ideas on social as well as gender identity in the defining process. He assumes identity is the essential element for social life and contends that individual identity embodied in self and away from social context has no sense.

People are unique but self is utterly made in society through initial and secondary socialization as well as current social processes in framework of which people define and redefine selves and others in their lives.

Richard Jenkins' theories have been inspired by theories of Erving Goffman (1969), Frederik Barth (1969), Pierre Bourdieu (second edition, 2002) and others. He believes what constitutes one's identity is what others see in them. In this situation, the study of the influence of structural and basic elements such as family, education, employment and media especially in metropolitan areas which are more under the influence of modernity can reveal the nature of these institutions in formation or reformation of identity of women from one side and show which layer of women and to what extent they resist traditional identities and make an attempt to create new identities actively and consciously.

\subsection{Social Identity}

The theory of social identity was first introduced in 1979 by Henri Tajfel and John Turner. The theoreticians of this perspective believe that membership in a group can lead to the reinforcement of personality, self-identification and the formation of personal classification in people. The most distinct difference between personal and social identity is that personal identity emphasises difference and the public one emphasises similarity (Jenkins, 2003).

Erving Goffman (1969) believes birth is a stage when an embodied human enters social world. The individual identity of a child is placed in the framework of mass identities. Gender is also one of the most common classifications of life opportunities and gender identity is not an individual identity but a social one since gender like other socio-cultural symbols is based on gender differences and requires certain conditions for life opportunities and experiences of all people, thus sexual difference is a biological entity and gender differences are of cultural type. Accordingly, gender identity refers to the attitudes and behaviours of one in regard to his or her gender which is shaped through socio-cultural conditions. As a result, gender is the most obvious aspect of individual identity which is formed in relation with others. In this regard Catharine A. MacKinnon (1987) conceptualizes gender as socially constructed. So, gender is one of the most common classifications and probably the most comprehensive one. As a preliminary social identity, gender organises one's experiences and merges them in itself (Jenkins, 2003).

This self and mind are the product of interacting with others. It should be noted that using communication media includes the creation of a new form of social relations with self and others. In public view regarding people's interaction with each other in society, women are to look after their husbands and children (a social construct) and men are the bread winners of the family. The social welfare policies are based on the premises that people live according to these norms which is the accepted approach (Abbott \& Wallace, 2005). 
However, Judith Butler (1990) contends that efforts to illustrate women as a particular and unified group only reinforce binary views of gender, and due to this limitation do not include other more fluid or subversive possibilities of the formation of gender and sexuality. There are several remarkable similarities between Butler's notion of identity and that of Goffman, which is apparently a more traditional one. In a similar manner to Goffman, Butler also argues that identity is achieved but she does not seem to imply that there is a back-stage personal identity that is more precise than that of everyday social life. Although some theorists may disagree, Butler's ideas have a lot in common with the social identity theories. An example is the idea of identity as an ongoing process; something that is permanently under construction. From both perspectives, identity is something we could become, rather than simply something we are.

Today's lifestyle is reflected and regenerated through media. Let's look at the main question again. What type of relationship exists between consumption pattern, motivation to use and degree of consumption of media from one side and women's attitude towards their gender identity from the other? Individuals will get an understanding of their being as a man or woman via their interaction with the others around them. Therefore, the main factor in identifying gender identity in this perspective is the relationship and the interaction between one and his/her social world. According to Roland Barthes (1975) all the social interaction and relation manifestations are based on the generation and consumption of symbols. In addition, one of the ways these symbols are transferred is that of media.

\section{Cyberfeminism}

The growing use of information technology by women has been extensively challenged. More widely, in gender study these two axioms have been profoundly discussed:

a) That the internet represents a new social organization for women, in which established forms of economic, political and social activities have been basically altered, and

b) The assumption that this betterment is an offspring of technology

Consequently the current feminist inspired situation is a debate about new technology and gender in order to answer whether or not technologies empower women in their liberation project.

Along with Third Wave Feminism, New Feminism and Power Feminism which were articulated in the course of the 1990s, Cyber Feminism has also been easily reached for diverse groups of women, young women in particular (cf. Gillis, 2004). Cyberfeminism indicates women's appreciation of information and computer technology on both practical and theoretical level. Some researchers have critically focused on gendered power relations in digital technologies (Paasonen, 2011). There have been multiple and often contradictory meanings and assumptions for the expression but generally feminist studies of new media are examining the mutually dependence of gender, embodiment and technology.

In the feminist perspectives there are two paradoxical aspects of treating technological developments; one that is sceptical of them and one that welcomes them enthusiastically in cyberspace (Turkle, 1993). In fact the admirers of cyberspace are united within the cyberfeminism. They rely on the internet as a space where all voices are equal and power becomes imaginary (Gur-Zeev, 1999). They assert that technological innovation has affected 
the balance of forces and contributed to the empowerment of women. It has been using effectively for the reproduction of the hierarchies of social, economic, political and gender power. Although Cyberfeminism addresses the complex new social conditions which have been created by global technologies, it develops much further than just creating new formulations of feminist theory and practice (Wilding, 1999). In line with the proven role of digital networks in feminist movements, technology enables women to participate meaningfully for their voice to be heard (Harcourt, 1999). Some researchers have contended that internet has the potential to entirely redefine the traditional gender roles, especially for those women who have limited skills or those who lack the resources to get proper higher education (Kelkar \& Nathan, 2002).

Sherry Turkle (1993) is optimistic about the emancipatory potential of the internet for women since it allows for the construction and reconstruction of identity to take place anew. Internet has a high potential to increase the information load people could get and this could enable women to redefine patriarchal gender roles while questioning institutions constraining them. According to this view, the Internet facilitates new forms of life during which one creates and re-creates identities consequently internet users are gender-less when they are in virtual space which frees them of any constraints and enables them to create new identities.

In this regard several feminist scholarships are seeing important opportunities for women's empowerment. It is said that internet opens up a window for women to the world outside. They have easy and direct access to information without any censorship just like men (Sharma, 2003). Judy Wajcman (1991), meanwhile, argues for a more subtle, complex, and relational approach to technology, one that allows space for women's agency. Some scholars such as Sadie Plant (1998) go so far as to say that cyberspace is more feminine in nature which is why women find this space convenient to work in. Hence, more recent schools of thought have encouraged a reconciliation of the feminist views of technology and remembering how virtual sphere might help them. Such point of view presumes that not only can media be used for the self-expression of one, but also it can help with the exploration of one's real self.

\section{Media}

Medium or communication device or it's plural as media or communication devices come from Latin and has entered Anglo-Saxon lexicon mysteriously with a general meaning of transferring through communication devices including numerous forms.

Mass media is paid attention to by the majority and refer to communication devices which have been invented and utilised in recent civilizations. The major characteristics of them are their strength and world-wildness (Hodkinson, 2011).

Mass media are considered as sources of power nowadays. They are devices to control management and innovation in the society which can replace power or other sources. Media are the platform for cultural developments either as art and symbolic signs or models, behaviours, lifestyles and norms. Media have also been transformed as the major sources of definitions and images of social facts for individuals, communities and societies. They present their value judgments together with news and entertainment in an indispensable manner (Fuchs \& Sandoval, 2014). The role and impact of media are partly determined by its 
use. There are also intrinsic constraints shaped by social interests of those who control its production and circulation which limit its functionality (Garnham, 2000).

The approximate definition of media can be grasped through stating some of their characteristics.

1. Media are to circulate variety of knowledge. They also act as other epistemological symbols.

2. Compared to other institutions, media influence more audience and allot more time for them.

3. More than other institutions, mass media produce a daily and continual extent of unity in appreciating facts (Fuchs \& Sandoval, 2014).

4. Media have had a role in losing local belongings and other identity institutions in today's world.

5. Media can replace symbolic and ritual aspects of local communities by offering subjects for discussions and characters for simulate

6. Media circulate messages which influence society's cultures and reflect them.

7. Media signify cognitive interconnectors since they come between the interlocutor and the world (Littlejohn \& Foss, 2011).

8. Media can revolutionize the private and public areas of life through their presence in everyday life of people. There are apparently three major roles for media in daily life:

- Media can contribute to the process of identity formation

- Media can contribute to the process of meaning seeking

- Media contribute to the regulation of daily life. Daily life is based on habits and media are used to bestow regularity to life (Gibbins \& Bo Reimer, 1999).

As a result every media functions according to the certain prevailing structure of socio-cultural relations and conditions. Media and their utilisation patterns together with various types of media content are intertwined with our identity. Mass media are powerful factors in socialization. Media often function as a bridge between our personal and private life from one side and the public world from the other. Media impact our general understanding of the world since they are the interconnectors of individual awareness and a vaster social construct and thus meaning making.

\section{Iranian Women and Changing the Identity}

Iran was one of the early adopters of the Internet in the Middle East with 43 million Internet users, including Internet Cafe Users (Internet World Stats 2012). However Iran has only one public internet service provider (ISP). The government has intentionally limited the bandwidth as a means of pre-cautionary measures. According to an Iranian newspaper, the number of filtered websites increased from five million in 2008 to ten million in 2009 (Sarmayeh Newspaper, 2009). Meanwhile, the range of internet users has grown considerably more diverse in terms of location, age, gender, class and ethnicity in comparison to the past. Mobile internet applications have been crucial to this transformation.

Today, we see the ever-increasing use of the internet as an essential medium in Iran. According to a recent report from Majles (parliament) research, rules and regulations 
concerning the internet have lost their force. According to the same report, until mid 1380's (2005-2010) the users of the internet were after entertainment, however they are now using the net to get informed of the latest news and get fed by analytical and intellectual merits of them which has concerned Iranian governors.

On the one hand, the minor benefit of internet for women is that through internet they have easier access to a wider range of goods and services, on the other hand, they are empowered in a sense to be highly acknowledged citizens; they use the technology to engage socially, to communicate their views to a wider audience and also to get involved in political activities. In so doing, women's blogging played a significant role in the early days of the Internet space. Female bloggers, predominantly the young, were among the pioneers in Iran (Annabelle \& Sreberny, 2010). They have created a network inside and outside Iran through internet sites which enable them to discuss women issues and draw attention to the plight of Iranian women in the context of global communication. Susannah Stern (2008) believes that these activities can provide significant chances for self-reflection and self-realization.

Such contributions in Iran are not dominated by reformist voices (Kelly \& Etling, 2008); however, they enable women to develop their identities. In reality, Internet in Iran is a replacement for the existence of Iranian women in society to be able to continue their activities and manoeuvres in different stages of life and in this kind of society that all kinds of activities outside their house and family have made things difficult for women.

There are some limited degrees of social opportunities for women in such a political and cultural context to construct an identity that can reflect their own selves. Despite the limitations, Iranian women have taken the maximum advantages of these few opportunities; and according to Haleh Afshar, in Islam and Feminisms: an Iranian Case-Study "over the decades the campaigning Islamist and secular women through the internet have gradually made it unacceptable for any government in Iran to exclude them from the public arena" (Afshar, 1999). Or in Meena Sharify-Funk's (2005) words the internet provides such opportunities for women to develop a sense of transnational identity. The transnational is not limited to geographical or cultural contexts.

Nowadays identity issues for Iranian women have become even more complex as female enrolment in educational institutions have increased significantly at all levels. More than 60 precents of new university students are women (Dabashi, 2010). However there is an ongoing paradox that the Islamic regime encourages the education of women and public participation but limits women's legal rights. Tradition and ideology are regulating Iranian women's daily life which makes them segregated but not prohibited, educated but legally subordinated and finally prepared to pursue a career but expected to submit to traditional gender roles (Nouraie-Simone, 2005). But the internet helps Iranian women to create or re-create new identities which identities hinge on religious tradition within the family structure. In so doing women use the internet as a free space to redefine them as they are able to create a virtual identity without the fear of being recognised and consequently punished.

On the internet women find themselves surrounded by others who have different ideas and values. At this stage they should identify themselves again because of the new understanding of their identity through dialogue. 'Identity is developed by the individual, but it has to be recognized and confirmed by others' (Buckingham, 2008). Dialogue between self and other 
could open up new horizons for creating a sense of self consciousness. The Internet transcends the more limited statist national identity in order to explore, live, illustrate and act on such an identity. When they know that there are other ways of being in Muslim contexts (Sharify-Funk, 2005). In other words, due to the emergence of postmodern thought along with new popular ideologies, more women have felt inclined to reclaim their identities. Hence 'the technology is seen to create new forms of community and civic life and offer immense resources for personal liberation and empowerment' (Buckingham, 2008, p. 31). Women can express their experiences and formulate their opinions in the virtual sphere and articulate their concerns and develop new ideas by getting feedbacks from others.

To make this argument even more strong it is possible to take a look at a new campaign that has been established a couple months ago on Facebook which more than 666000 people have liked it. My Stealthy Freedom is the name of the Facebook page where women try to show different identity than what they inherited via traditions and rules. The women, whose names are not revealed, share their moment of stealthy freedom in short texts and a photo. As Jenkins (2003) estimated, hoping to actively and wilfully create new identities, these women have courageously posted their photos in their moments of "stealthy freedom" without a veil which could bring them imprisonment and punishment for violating the strict Islamic dress code. It is important to consider that veil is an extensive part of Iranian woman's identity. Some scholars believe that Islamic culture, the imposed veil for example, deconstructs women's self-identity, and reconstructs and identity of obedience for them (Shirazi, 2003).

However, these courageous women have shocked the world by this campaign since Facebook has approximately one billion and three hundred thousand users now which are slightly bigger than the population of China. The number of photos and comments is one hundred thirty five and five hundred and ten times more than the number of articles published respectively. According to a report in 2012, one thousand pieces of news and thirty five thousand photos and videos were uploaded on Facebook every sixty seconds during which five hundred and ten thousand comments and twenty three thousand messages were also communicated. Therefore the popularity of Facebook has helped Iranian women to grab the world's attention. For instance the Washington post news struck most by three things in the images published on "Stealthy Freedoms": the multiple generations of women in the pictures, the sympathetic and supportive comments posted by men and the photos showing couples. Hence this Facebook page is another sign of cyber spaces power which makes Iranian women fearless enough to see that they are not alone with their beliefs and choices.

An Iranian woman's ability to make these trivial changes requires her to have some degree of control over her body, mind and lived experiences and not controlled by a state-run religious doctrine which possesses all physical and mental parts of her life. In women's outdoor photos, they can be seen without Hijab accompanied by captions describing the lack of freedom embodied in having to wear a hijab, or what it means to be briefly removing it in public which celebrate the freedom from Hijab. In those images they no longer identify themselves with being a traditional Islamic woman; they are now representing a new version of Iranian women who redefine their identity through a combination of modern and traditional attitude. This virtual interaction between the sender and her viewers also proves that women are able, through internet, to present a new identity and role for themselves. 
Therefore, some non-conformity and acts of disobedience allow Iranian women to develop their identity via opposition with the government and enable them to construct their identities against the impositions such as very strict rules of Hijab, and severe rules of so called "standard" norms and behaviours. Women have daily struggled against subjective rules and margins to overcome the oppression of rules and traditions which manipulate them. It seems they are now able to distinguish their true self. As this may imply their new identity is created parallel with their peers who have the same concerns and issues.

In this regards a focus on identity entails us to pay attention to the diverse ways in which media and technologies are used in everyday life and their implications both for individuals and for society. This also requires that we see women as significant social agents who impact the society their own ways. Therefore clear, unemotional, logical and positively critical approach is required for understanding the role and impact of digital media in the formation of women's identities.

However, it should be mentioned that the virtual sphere has various disadvantages as well as the advantages. At the same time we choose to explore this new cyberspace, we need to proceed with caution to avoid the diversionary and seductive allure of the open road. Since Individuals who might never have opportunity to share minority thoughts or feelings with others of similar "culture" suddenly have global culture pool to draw from. For example, a teenager in a small town who comes into an awareness of lesbian identity may have no local lesbian culture to relate to.

\section{Conclusions}

Through an examination of the Iranian women's activities until recent times, one can observe that women have jumped on the band wagon via recognizing the significance of the internet and as always have used it to achieve more success towards their goals. In spite of the governments suppress and control over internet, Iranian female activists have not given up hope in achieving their aims and well demonstrated the fact that they are well familiar with the new trend of the net and can familiarize themselves with ways to use technology to attain their objectives.

Admittedly, in this traditionally male-dominated part of the world, women have gradually risen from being just mothers and housewives confined mainly to the private spheres of their families, to becoming influential players in public life. New media offer decent promises for women ability to construct their identities on their own in the public sphere. To give an instance, Facebook content indeed indicates information of self-presentation and personal documentation of everyday lives of users. Facebook acts as an archive of social relationships and provides a means of recording ongoing interactions. It is a way of archiving the self, storing biography and enhancing social memory. Thus, Facebook can offer a record of the texture of individuals' daily lives or at least a view of life that users wish to portray.

To sum up, cyberspace represents a new glimpse of hope for many marginalized groups, including women. The interactive and open nature of this virtual environment gives those groups opportunities for independent representation of themselves, and a potential for introducing new identities. 


\section{References}

Abdo, G. (2010). Dealing with Iran: Time for middle way between confrontation and conciliation. The century foundation, Retrieved May 26, 2014, from www.tcf.org/publications/internationalaffairs/dealingwiran.pdf

Abbott, P., Wallace, C., \& Tyler, M. (2005). An introduction to scociology: Feminist perspectives(3rd ed.). New York: Routledge.

Afshar, H. (1999). Islam and Feminisms: An Iranian Case-Study. London: MacMillan.

Alavi, N. (2006). We are Iran. London : Portobello.

Amir-Ebrahimi, M. ( 2008). Blogging from Qom: Behind walls and veils. Comparative Studies of South Asia, Africa and the Middle East, 28(2), 235-249. http://dx.doi.org/10.1215/1089201x-2008-002

Annabelle, S., \& Sreberny, A. (2010). Blogistan : the internet and politics in Iran. New York: London.

Asemi A. (2006). Information technology and national development in Iran, presented at the International Conference on Hybrid Information Technology, Computers and Society, 558-565, retrieved October $15, \quad 2009$, from http://ieeexplore.ieee.org/stamp/stamp.jsp?tp=\&arnumber=4021147\&isnumber=4021047?tag $=1 \& \operatorname{tag}=1$

Barlow, R. (2012). Women's human rights and the muslim question: Iran's one million signaturees campaign. Australia: Melbourne university press.

Barthes, R. (1975). The pleasure of the text. Canada: Harper Collins Canada Ltd.

Buckingham, D. (2008). "Introducing Identity." Youth, Identity, and Digital Media. In David Buckingham. The John D. and Catherine T. MacArthur Foundation Series on Digital Media and Learning (pp. 1-24). Cambridge, MA: The MIT Press.

Dabashi, H. (2010). Iran the green movement and the USA: the fox and the paradox. Zed books Ltd.

Deegan, M. J. (2014). Goffman on Gender, Sexism, and Feminism: A Summary of Notes on a Conversation with Erving Goffman and My Reflections Then and Now, Wiley-Blackwell. 37(1), 71-86.

Freud, S. (2001). New identity for the new century. In: family in society, New York.

Fuchs, C., \& Sandoval, M. (2014). Critique, Social Media and the Information Society. New York: Routledge.

Gibbins, John R., \& Bo Reimer. (1999). The Politics of Postmodernity. An Introduction to Contemporary Politics and Culture. London: Sage.

Giddens, A. (1991). Modernity and Self-Identity, Cambridge, UK: Polity.

Gillis, S. (2004). Neither Cyborg Nor Goddess: The (Im) Possibilities of Cyberfeminism. In S. Gillis, G. Howie \& R. Munford (Eds.), Third wave feminism: A Critical Exploration. London: Palgrave. http://dx.doi.org/10.1057/9780230523173

Garnham, N. (2000). Information Society as Theory or Ideology, Information, Communication and Society, 3(2), 139-152. http://dx.doi.org/10.1080/13691180050123677 
Gur-Zeev, I. (1999). Cyberfeminism and education in the era of the exile of spirit. Education theory, 49, 437-455. http://dx.doi.org/10.1111/j.1741-5446.1999.00437.x

Hadkinson, P. (2011). Media, culture and society: An introduction. London: Sage publications Ltd.

Hall. S., \& Geben. B., (1992). Formation of modernity. Cambridge: polity press.

Harcourt, W. (1999). Women@Internet, Palgrave Macmillan.

Harcourt, W. (2011). Using the master's tools: women's movements and social media. Media Development, 58(1), 19-22.

Hendelman-Baavur, L. (2007). Promise and perils of Weblogistan: online personal journals and the Islamic Republic of Iran, Middle East Review of International affairs, 11(2). Retrieved August 12, 2014, from http://www.gloria-center.org/2007/06/hendelman-baavur-2007-06-06/

Jenkins, R. (2003). Social identity (3rd ed.). New York: Routledg.

Johari A. (2002). Internet use in Iran: Access, social, and educational issues. Journal of Educational Technology Research and Development, 49(5). http://dx.doi.org/10.1007/BF02504963

Judith, B. (1990). Gender Trouble. London: Routledge.

Kelly, J., \& Etling, B. (2008). Maping Iran's online public: Politics and culture in the pesian blogosphere, Cambridge, MA: Harward Law School.

Kelkar, G., \& Nathan, D. (2002). Gender relations and technological change in Asia. Current Sociology, 50(3), 427-441.

Kolko, B. E., Nakamura, L., \& Rodman (2000). Race in cyberspace. New York: Routledge.

Littlejohn, S., \& Foss, K. (2011). Theories of Human Communication. America: Waveland Press.

MacKinnon, C. (1982). Feminism, Marxism, Method, and the State: An Agenda for Theory. 7 Signs 515; and Catharine A. MacKinnon, Feminism Unmodified (Cambridge, MA: Harvard University Press, 1987).

Mojab, S. (2001). The politics of cyberfeminism in the middle east: the case of Kurdish women. Race gender \& class, 8(4), 42-61.

Nouraei-Simone, F. (2005). On shifting ground: Muslim women in the global era. New York: Feminist press.

Paasonen, S. (2011). Revisiting cyberfeminism. Communications, 36, 335-352. http://dx.doi.org/10.1515/comm.2011.017

Pilcher, J., \& Whele Han, I. (2005). 50 key concepts in gender studies. London: sage.

Plant, S. (1996). On the matrix: Cyberfeminist simulations. In R. Shields (Ed.), Cultures of internet: Virtual spaces, real histories, living bodies (pp. 170 183). London: Sage.

Plant, S. (1997). Zeros ones: Digital women and the new technoculture. London: Fourth Estate.

Plant, S. (1996). The Future Looms: Weaving Women and Cybernetics. In L. H. Leeson (Ed.), Clicking In: Hot Links to a Digital Culture (pp. 123-135). Washington: Bay Press. 
Plant, S. (1999). Das netz ist weiblich (the net is feminine).

Sharify-Funk, M. (2005). Women and the dynamics of transnational networks. Nouraie-Simone, F, on shifting grounds: Muslim women in the global era (pp. 248-267). New York: The feminist Press.

Sharma, U. (2003). Women empowerment through information technology. Authors Press.

Shirazi, F. (2003). The veil unveiled: The hijab in modern culture. University Press of Florida

Stephan, R. (2013). Creating solidarity in cyberspace: The case of arab women's solidarity association united. Journal of middle east women's studies, 9(1), 81-109. http://dx.doi.org/10.2979/jmiddeastwomstud.9.1.81

Stern, S. (2008). Producing Sites, Exploring Identities: Youth Online Authorship. Youth, Identity, and Digital Media. Edited by David Buckingham. The John D. and Catherine T. MacArthur Foundation Series on Digital Media and Learning. Cambridge, MA: The MIT Press. 95-118.

Tajfel, H., \& Turner, J. C. (1979). An integrative theory of intergroup conflict. The social psychology of intergroup relations, 33, 47.

Thompson, J. B. (1995). The Media and Modernity: A Social Theory of the Media. Stanford, California: Polity Press.

Turkle, S. (1993). Life on the screen: identity in the age of the internet. New York: Simon and Schuster.

Wajcman, J. (1991). Feminist Critiques of Science and Technology. University Park, PA: Pennsylvania State University Press.

Wajcman, J. (2004). Male Designs on Technology. Cambridge, UK: Polity Press.

Wilding, F., \& Critical Art Ensemble. (1998). Notes on the political condition of cyberfeminism. In C. Sollfrank \& Old Boys Network (Eds.), First cyberfeminist international. Hamburg: OBN.

Wood ward, K. (2000). Questioning identity. London: Published Rutledge.

\section{Copyright Disclaimer}

Copyright reserved by the author(s).

This article is an open-access article distributed under the terms and conditions of the Creative Commons Attribution license (http://creativecommons.org/licenses/by/3.0/). 